\title{
BMJ Open Understanding the perspectives and values of midwives, obstetricians and obstetric registrars regarding episiotomy: qualitative interview study
}

\author{
Anna Seijmonsbergen-Schermers (D) , ${ }^{1}$ Suzanne Thompson, ${ }^{2}$ \\ Esther Feijen-de Jong, ${ }^{3}$ Marrit Smit, ${ }^{4}$ Marianne Prins, ${ }^{5}$ Thomas van den Akker, ${ }^{4,6}$ \\ Ank de Jonge ${ }^{1}$
}

To cite: SeijmonsbergenSchermers A, Thompson S, Feijen-de Jong $\mathrm{E}$, et al. Understanding the perspectives and values of midwives, obstetricians and obstetric registrars regarding episiotomy: qualitative interview study. BMJ Open 2021;11:e037536. doi:10.1136/ bmjopen-2020-037536

- Prepublication history and additional material for this paper is available online. To view these files, please visit the journal online (http://dx.doi.org/10. 1136/bmjopen-2020-037536).

Received 28 February 2020 Revised 26 0ctober 2020 Accepted 16 November 2020

Check for updates

(c) Author(s) (or their employer(s)) 2021. Re-use permitted under CC BY-NC. No commercial re-use. See rights and permissions. Published by BMJ.

For numbered affiliations see end of article.

\section{Correspondence to}

Mrs Anna Seijmonsbergen-

Schermers:

a.seijmonsbergen@

amsterdamumc.nl

\section{ABSTRACT}

Objectives Insight into perspectives and values of care providers on episiotomy can be a first step towards reducing variation in its use. We aimed to gain insight into these perspectives and values.

Setting Maternity care in the Netherlands.

Participants Midwives, obstetricians and obstetric registrars working in primary, secondary or tertiary care, purposively sampled, based on their perceived episiotomy rate and/or region of work.

\section{Primary and secondary outcome}

measures Perspectives and values of care providers which were explored using semistructured in-depth interviews.

Results The following four themes were identified, using the evidence-based practice-model of Satterfield et al as a framework: 'Care providers' vision on childbirth', 'Discrepancy between restrictive perspective and daily practice', 'Clinical expertise versus literature-based practice' and 'Involvement of women in the decision'. Perspectives, values and practices regarding episiotomy were strongly influenced by care providers' underlying visions on childbirth. Although care providers often emphasised the importance of restrictive episiotomy policy, a discrepancy was found between this vision and the large number of varying indications for episiotomy. Although on one hand care providers cited evidence to support their practice, on the other hand, many based their decisionmaking to a larger extent on clinical experience. Although most care providers considered women's autonomy to be important, at the moment of deciding on episiotomy, the involvement of women in the decision was perceived as minimal, and real informed consent generally did not take place, neither during labour, nor prenatally. Many care providers belittled episiotomy in their language.

Conclusions Care providers' underlying vision on episiotomy and childbirth was an important contributor to the large variations in episiotomy usage. Their clinical expertise was a more important component in decisionmaking on episiotomy than the literature. Women were minimally involved in the decision for performing episiotomy. More research is required to achieve consensus on indications for episiotomy.
Strengths and limitations of this study

- The strength of this qualitative study is that it represents perspectives and values of care providers from all professional backgrounds.

- Because this study was conducted in the Netherlands, generalisability of results cannot be assumed, but these are relevant to a broad context, since variation in episiotomy exists in many countries.

- A limitation of this study is that perspectives of the interviewers may have encouraged participants to give socially desirable answers or express strong opposite opinions.

- Conversely, by being an expert on the topic, the interviewer was able to understand the participants.

- Although data saturation was reached, an element of selection bias cannot be eliminated.

\section{INTRODUCTION}

Episiotomy is one of the most commonly performed surgical interventions during childbirth, ${ }^{1}$ and is primarily used to expedite the second stage of labour. ${ }^{2}$ There is major variation in episiotomy practice worldwide, ${ }^{13}$ with rates varying from $4 \%$ in Denmark ${ }^{4}$ to $91 \%$ in Thailand. $^{5}$ The episiotomy rate in the Netherlands was $46 \%$ among nulliparous and $14 \%$ among multiparous women, with an instrumental-vaginal birth rate of $16 \%$ among nulliparous and 3\% among multiparous women in $2013 .{ }^{6}$ Rates varied among 12 regions from $14 \%$ to $42 \%$ for nulliparous women and from $3 \%$ to $13 \%$ for multiparous women. ${ }^{7}$ The WHO does not recommend routine or liberal use of episiotomy for women undergoing spontaneous vaginal birth. ${ }^{8}$ For instrumental births, episiotomy may be beneficial to prevent Obstetric Anal Sphincter Injury (OASI). ${ }^{9}$ Several studies illustrate that, in general, restrictive use of episiotomy 
is preferable to routine or liberal use. ${ }^{2}$ Episiotomies can lead to physical problems, such as postpartum urinary retention, perineal pain, dyspareunia and pelvic floor muscle strength. ${ }^{10-17}$ It is unknown which episiotomy rate is appropriate for obtaining an optimal balance between harm caused by episiotomy and prevention of maternal and neonatal morbidity by its use. Moreover, there is a lack of uniform recommendations on indications for performing episiotomy, and there is major variation in applied indications among care providers. ${ }^{11}$ This suggests that perspectives and values of care providers influence the decision to perform an episiotomy and that this decision is not only based on medical necessity. Studies into indications for episiotomy use or opinions of care providers have only been conducted among restricted subgroups of childbearing women or in settings that cannot be generalised. ${ }^{18-22}$ In these studies, many indications for performing episiotomy were reported, including fetal distress, instrumental birth, a tight or short perineum, prevention of major tears, history of major tears or episiotomy, delay in second stage of labour, breech presentation, shoulder dystocia, preterm birth, poor maternal effort, macrosomia, nulliparity, facilitation of postpartum wound repair, vaginal bleeding and women's request. ${ }^{18-23}$

Furthermore, it is still unknown which underlying perspectives and values of care providers have impact on the decision to perform episiotomy. Insight into these perspectives and values can be a first step towards optimising the balance between overuse and underuse of episiotomies. The aim of this qualitative study was to gain insight into perspectives and values of midwives, obstetricians and obstetric registrars with regard to performing episiotomy.

\section{METHODS}

\section{Design and setting}

To gain insight into the perspectives and values of care providers towards performing episiotomy, a qualitative study with a constructivist paradigm was conducted, using semistructured interviews. Choosing qualitative interviews involving face-to-face contact enabled an exploration of care providers' perspectives and values. ${ }^{24}$ An interpretivist approach was considered appropriate for this exploration. ${ }^{25}$

\section{Research team and reflexivity}

The first author interviewed 16 of the 20 participants and is a woman of 30 years, mother, midwife with 4 years of clinical experience, educated in conducting qualitative studies, and employed as a PhD candidate in her final year at the time of the study. Most of the participants were unknown to her, but two of the participants were aware of her previous publications on episiotomy in the Netherlands. The first interview was carried out by the first and second author together and one interview was carried out by the second author, who is a woman of 49 years, midwife with 26 years clinical experience, experienced qualitative interviewer, lecturer and employed as a $\mathrm{PhD}$ candidate in her final year at the time of the study. Three interviews were conducted by third-year midwifery students. They were educated on interview techniques in advance, and were instructed by the first author.

The entire research team consisted of researchers from different disciplines, including midwives, researchers, lecturers and an obstetrician. A topic list was developed by the first author, reviewed by the research team and iteratively evolved based on the findings of the interviews.

\section{Recruitment}

Participants were eligible if they were working as a midwife in primary or secondary care, obstetrician or obstetrician/urogynaecologist in secondary or tertiary care, or as an obstetric registrar. Purposive and snowball sampling strategies were applied, to obtain a broad sample of care providers, reflecting the possible diversity of perspectives and values. To ensure variety among participants, purposive sampling was based on care providers' perceived episiotomy rate and/or region of work. Participants were randomly approached by contacting care providers in specific regions, or purposively approached through referrals by other care providers. Participants were recruited until data saturation was obtained, which was defined by the absence of new codes, and until all parts of the country were represented. A total of 34 care providers, hospitals or midwifery practices were contacted, resulting in 20 included participants. Reasons for non-participation were: no response received, retired, lack of time and not having the perceived episiotomy rate that was still required to obtain a varied sample of participants. In advance of the interviews, participants were asked to provide personal information on place of education, region of work, number of attended births per year and their personal episiotomy rate or number of episiotomies performed during the last 25 attended births. An 'attended birth' was specified to the participants as a birth where the decision to perform an episiotomy would be made by themselves. Participants were approached by email, telephone or both. A brief overview of the aim of the interview was given before the care provider agreed to participate. The participant was informed that it would concern an individual in-depth interview, participation would be voluntary, data would be anonymised and treated confidentially, and audio material would be destroyed following transcription. Data and participant names were stored separately with encrypted passwords and transcripts were shared with students for transcription with encrypted passwords.

\section{Interviews}

Interviews were semistructured, using a topic-list with open-ended questions, which was pilot tested (see box 1). The participant was informed that (s)he could withdraw from the study without giving a reason and written informed consent was obtained after oral and written information about the study (see online supplemental 


\section{Box 1 Topic list of the interviews}

\section{Grand tour question: Can you tell me about your opinion towards episiotomy? \\ Indications: \\ - Own reasons for performing episiotomy. \\ - Opinion on reasons for others to perform episiotomy. \\ Prevention of spontaneous ruptures \\ - How? \\ - Role of episiotomy. \\ - Technique.}

\section{Own experiences and feelings}

- Own feelings when performing episiotomy

- Colleagues, working environment, work culture.

- Changes in opinion and acting.

The childbearing woman

- Addressing episiotomy.

- Birthing plan.

- Informed consent.

- Women's preferences; deviating preferences.

- Unnecessary use of episiotomy by other care providers

Context

Opinion towards episiotomy rates and usage in the Netherlands.

files 1 and 2). At the start of the interview, the participants were informed that the aim of the interview was to investigate the full scope of perspectives and values of care providers, that no value judgement would be made during the interview, and that there was no right or wrong answer. Besides, they were told that the perspectives and values of the interviewer would not be part of the conversation. The interview commenced with an invitation to the participant to talk about his/her opinion regarding episiotomy. Subsequently, in the responses given by the participant, the researchers probed, in order to elicit depth, based on the topics that were brought up by the participant.

Interviews were recorded on audio equipment and transcribed verbatim by the first author or by student assistants.

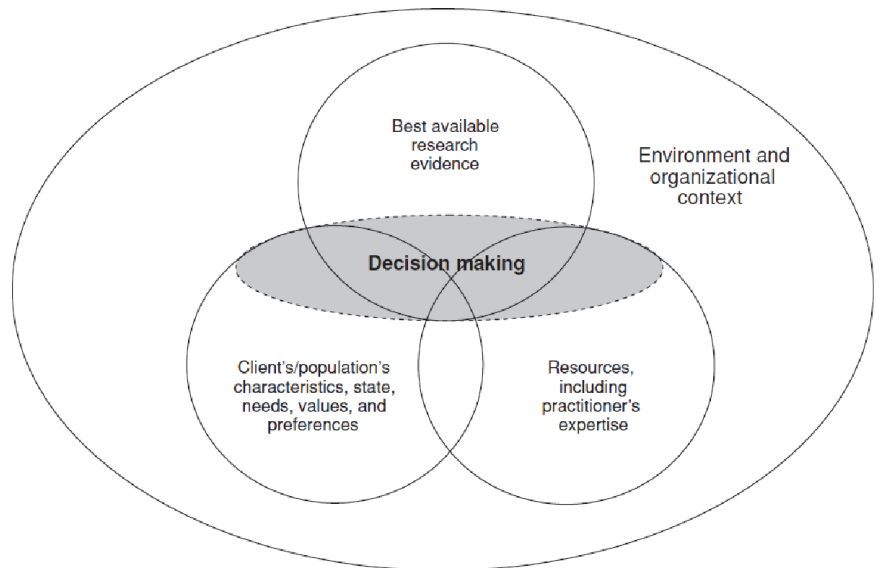

Figure 1 The revised model on evidence-based practice of Attride-Stirling. ${ }^{27}$
Field notes were made during and after the interviews. To ensure accuracy and to facilitate deep engagement with the data, transcripts of interviews that were recorded by student assistants, were read and re-read, before being checked with the original audio by the first author. After each interview, member check was offered to the participant based on the transcript of each interview, as a means of maintaining scientific rigour, which did not lead to responses in which changes were requested.

\section{Analysis}

Data analysis was carried out concurrently with data collection, allowing the researchers to reflect on the data. This allowed for the exploration and validation of emerging themes which were identified from the interviews and which were used iteratively to adjust the topic list for subsequent interviews. The first interviews were analysed independently by the first two authors, and disagreements about codes were discussed until consensus was reached.

Inductive thematic analysis was conducted, described by Braun and Clarke, ${ }^{26}$ making use of statistic software programme MAXQDA. Data were read and re-read to become familiarised with them. Initial codes were generated by coding interesting features of the data and relationships between codes were identified. A first coding tree was developed, and the first five interviews were coded again to identify overarching codes. During the analyses of the subsequent interviews, the codes were increasingly collated into potential themes and all data relevant to each theme were gathered. After potential themes were identified, these were reviewed by checking the relation to the coded extracts and the entire data set, generating a thematic network. ${ }^{27}$ Subsequently, the authors applied a name and a description for each theme (see the coding tree in online supplemental file 3). Quotes were identified, providing thick description as a means of illustrating these themes. During this data collection and analysis process, discussion of and reflection on the codes, subthemes, and themes were ongoing between the researchers involved in this study. For framing the results into the existing literature, we compared the data to the framework of evidence-based practice (EBP), using the model of Satterfield $e t a l^{28}$ (figure 1). This model includes the following three components: Best available research evidence', 'Client's/population's characteristics, state, needs, values, and preferences', and 'Resources, including practitioner's expertise'. These three components overlap in the centre, which illustrates the way decisions are made. The fourth component 'Environmental and organizational contexts', which is places in the outer space of the model, has influence on all components.

\section{Patient involvement}

Patients were not involved in this study. 


\begin{tabular}{|c|c|}
\hline Characteristic & Summary of participants \\
\hline \multirow[t]{2}{*}{ Gender } & 13 women \\
\hline & 7 men \\
\hline Age & Ranging from 25 to 56 years \\
\hline \multirow[t]{8}{*}{ Profession } & $\begin{array}{l}5 \text { midwives, working in primary } \\
\text { care }\end{array}$ \\
\hline & $\begin{array}{l}4 \text { midwives, working in secondary } \\
\text { care }\end{array}$ \\
\hline & $\begin{array}{l}1 \text { midwife, working in both primary } \\
\text { and secondary care }\end{array}$ \\
\hline & $\begin{array}{l}3 \text { obstetricians, working in } \\
\text { secondary care }\end{array}$ \\
\hline & $\begin{array}{l}1 \text { obstetrician, working in tertiary } \\
\text { care }\end{array}$ \\
\hline & $\begin{array}{l}1 \text { obstetric registrar, in sixth year, } \\
\text { working in secondary care }\end{array}$ \\
\hline & $\begin{array}{l}3 \text { obstetric registrars, from first to } \\
\text { sixth year, working in tertiary care }\end{array}$ \\
\hline & $\begin{array}{l}2 \text { urogynaecologists, working in } \\
\text { secondary care }\end{array}$ \\
\hline Working experience & $\begin{array}{l}\text { Ranging from } 3 \text { months to } 29 \\
\text { years }\end{array}$ \\
\hline $\begin{array}{l}\text { Approximate number of } \\
\text { attended births a year }\end{array}$ & Ranging from 12 to 200 \\
\hline $\begin{array}{l}\text { Approximate personal } \\
\text { episiotomy rate }\end{array}$ & Ranging from $0 \%$ to $90 \%$ \\
\hline
\end{tabular}

\section{RESULTS}

Twenty of the 34 invited care providers gave consent and participated in the study, 13 women and 7 men (table 1). Ten were working as a midwife, in primary or secondary care, 6 were obstetricians, of which 2 were specialised in urogynaecology and 4 obstetric registrars ranging in educational experience from the first to sixth years of education. Participants were diverse with regard to ages, ranging from 25 to 55 years; work experience, from 3 months to 29 years; number of births attended per year, from 12 to 20; and their approximate personal episiotomy rate, from $0 \%$ to $90 \%$. The interviews took place between August 2017 and December 2019, at a quiet location, without other persons present, and convenient for the participant, which generally was the clinic or the participants' home. The interviews lasted between $33 \mathrm{~min}$ and 1 hour $55 \mathrm{~min}$.

Four themes giving insight into the perspective and values of care providers towards episiotomy emerged from the data. These were 'Care providers' vision on childbirth', 'Discrepancy between restrictive perspective and daily practice', 'Clinical expertise versus literaturebased practice', and 'Involvement of women in the decision'.

\section{Care providers' vision on childbirth}

The EBP-component 'Resources, including practitioner's expertise' was the most important component in the perspective and values of care providers. Care providers' visions on childbirth underpin their perspective and values about episiotomy use. Views on childbirth could be characterised in two paradigms: either a physiological vision, or a risk-focused vision.

The physiological vision was characterised by the importance of iatrogenic harm to healthy body tissues, avoiding episiotomies, and approaches in care that minimised episiotomy and spontaneous perineal rupture. Care providers with this vision more often articulated negative feelings that they associated with performing episiotomy. They stated that episiotomy should be avoided whenever possible.

Well, it really is a big injury that you cause to someone. We call it a little cut but, eh, I remember during my training, the gynaecologists said; "If you saw such an injury on someone in the street, you'd call an ambulance". (...] Yes, it's not nothing for a woman to have that. (Midwife 8)

And are there, for example, ways to learn how to perform fewer epi's (episiotomy), fewer interventions without disadvantaging the mother, sphincter damage, or for babies, fetal distress? ... Then we have to see if we can do that. (Obstetrician 9)

The risk-focused vision was characterised by a tendency to intervene. This approach emphasised the protective effect of episiotomy for the child, but more particularly for the mother. Care providers with this vision did not really articulate negative feelings when performing episiotomy. Rather, they considered it as a technical operation, resulting in a clean cut that was viewed by some care providers as preferable to a spontaneous perineal rupture.

No, I don't feel bad about it (episiotomy). I also don't necessarily feel bad for the woman because my idea is: "Well, if I suture well then I don't think there will be consequences". And I do it for a reason. The episiotomies I perform, I can justify them. And it's just a common, also very routine medical procedure that is just part of giving birth, so I don't feel like that... I feel no emotion about it. I perform it with professional distance. (Obstetric registrar 7)

Intrinsic and extrinsic factors contributed to care providers' visions on childbirth, and viewpoints were rather dynamic, evolving over time. Intrinsically, care providers often emphasised an eagerness to learn, but skills training mainly focused on suturing and not on performing episiotomy, and some did not attend professional training to update their skills. This division was also noted in reflection on episiotomy usage. Some professionals reflected on their use of episiotomy; others 
mentioned that episiotomy was never a subject of evaluation, neither for themselves, nor with colleagues.

Yes, I think at the start of your education you [...] follow the example of those who train you and you go along with that. And as your training progresses, you start looking around, like how is that? [...] And then you evaluate again: how did it go? Did it go well then? It'd gaining a bit of experience and learning from that. It isn't just about what you read in the scientific literature or what you know about other peoples' opinions, but also finding out for yourself. (Obstetrician 18)

No, we don't really correct each other, it (episiotomy) is not really a subject that regularly crops up... do you cut or don't you cut ... Or how many sphincter damages have you had, how many have I had... (Obstetrician 11)

Extrinsically, care providers mentioned the importance of two things in the evolution of their professional vision on childbirth. First, they highlighted that childbirth visions are highly influenced by professional and educational backgrounds. Second, they mentioned that working experience is an important contributor to quality of care and that adverse events influence the tendency to intervene.

I think that if you look towards gynaecologists who deal with the pelvic floor ... They deal with it very differently than the obstetricians. [...] I think eh ... pelvic floor gynecologists are more likely to perform episiotomy. (Obstetric registrar 2)

I think that if you've seen a lot of bad stuff and that is often so, in hospitals... if you see a lot of calamities, then you tend to cut earlier. (Midwife 4)

\section{Discrepancy between restrictive perspective and daily practice}

There was a discrepancy between what many care providers mentioned as their perspective and values regarding episiotomy, and their daily practice. Many care providers emphasised the importance of a restrictive approach, stating that it should only be performed where there is justifiable medical need. However, in total, many different justifications were mentioned as valid, suggesting that performing episiotomies only when medically justified, may result in high episiotomy rates and large interprofessional variations (see box 2). Care providers justified their episiotomy usage by balancing between the justification and the potential harm. They did this by weighing up maternal characteristics, the situation during the second stage of labour, medical technology and, to a lesser extent, women's preferences. If clearly indicated, care providers were confident that the episiotomy was justified, but feeling uncertain or inexperienced was mentioned as well.

Because actually, we can't really demonstrate that the female pelvic floor is better off being cut into, to

\section{Box 2 Indications mentioned by participants}

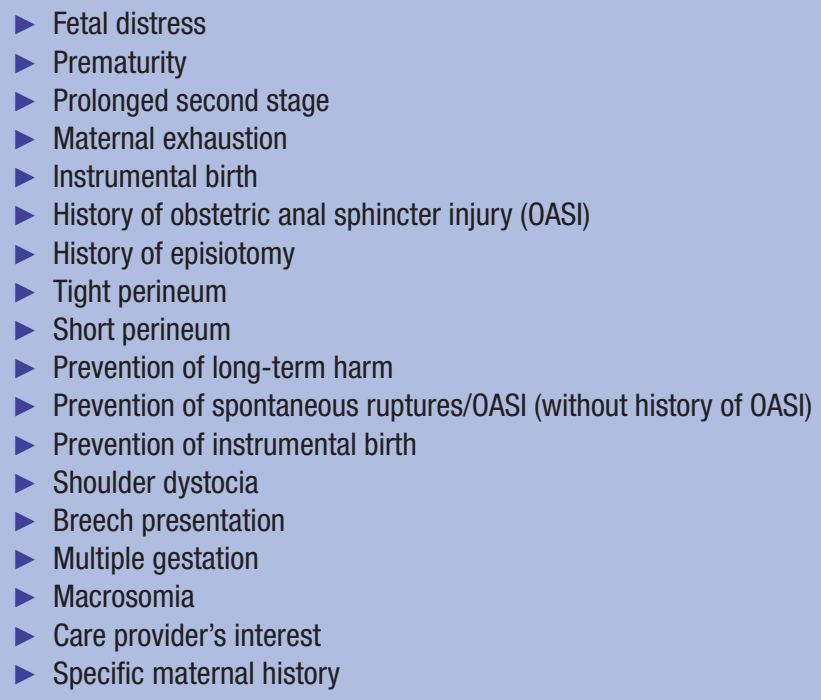

summarize. The female pelvic floor does not improve as a result of cutting and, eh, I sometimes grumble that we're the ones who have to suture when no-one else has the over-sight. And if it (the perineum) looks like a bomb went off there, guys, just perform episiotomy, don't let it tear like that. (Obstetrician 11)

And it, yes, it is bizarre that you affect someone's body in this way, eh, literally cut open. Eh, but with the goal of ultimately ensuring that someone has fewer problems in the future. So that's what makes it justifiable for me to do it. (Obstetrician/urogynaecologist 10).

The lack of evaluation of the longer term implications and feedback on the consequences of their episiotomies inhibited care providers in experiencing the need of being restrictive in performing episiotomy. The possibility to evaluate practice was seen as being limited by difficulties in comparing incidences of episiotomy between lowrisk and high-risk populations.

It's a pity that we have a lot of hospitals... Many births where we perform an epi, eh, we of course never see them again, sometimes at 6 weeks but sometimes not. That is of course a shame, because it is good to get feedback from what happens with an epi. (Obstetric registrar 7)

\section{Clinical expertise versus literature-based practice}

Care providers generally gave more weight to the 'practitioner expertise' component of EBP than the 'best available research' component in the decision-making for episiotomy. Care providers justified deviations from 'best available research' by pointing out the limitations of applying evidence to practice situations. Conversely, different care providers used literature differently to substantiate their own perspectives and values, resulting in varying techniques, methods, and approaches to women during the second stage of labour. 
Yes, eh, of course, eh, that we would only do it in cases of fetal distress. Eh well it sometimes happens that you, eh, have a very long second stage $[. .$.$] that you$ might need to make some space anyway. Then again, eh, during the birth you just see that, eh, the perineum, the pelvic floor is just very tight. Or it threatens to tear badly. You still hope that it (episiotomy) will prevent something worse. But of course that is not very evidence based. (Midwife 13)

It's the same when you look at eh, at the literature around elective use of episiotomy after previous sphincter damage $[\ldots]$, you will probably come to the conclusion that it doesn't prevent sphincter damage happening again, you need to look at what happens and how such a scar behaves during the birth. So, if it is completely rigid and very thin and you can almost see it tear when the head crowns, yes, then I wonder if that (the literature) also applies to that case. (Obstetrician 18)

At the moment of decision-making, the decision to perform episiotomy was based on the care providers' own clinical judgement. Despite having individual and often strong views and a personal way of working, the influence of colleagues on practice was mentioned as important. This is reflected by the EBP-component 'Environment and organizational context'. Mainly for those working in secondary or tertiary care, consultation and supervision of colleagues were an important factor in decision-making. On the other hand, working autonomously was expressed by other participants. Some of the care providers articulated the fear of being judged or the feeling of having to justify or 'account' for their decision-making.

So he (supervising doctor) said; "If in doubt, perform episiotomy." And I thought that was really a very simple encouragement. And not that I do it a lot, I don't think I did it then either, but I did remember thinking; "Oh yes, useful tip." And it is precisely when you are inexperienced that you should perhaps do more episiotomies so that you have babies in good condition. Better that than that you are too scared to do it and therefore get into difficulties. (Obstetric registrar 7)

I mean, I think ... the ... eh ... when you compare the studies with each other you might think: Yikes, it (episiotomy) happens way too much there (in the hospital) and you definitely shouldn't be in the hospital because there everyone is performing episiotomies all over the place. But I think, well, since I started working in the hospital, it's like comparing apples with oranges... I really find that so annoying! (Midwife 5)

\section{Involvement of women in the decision}

The EBP-component 'Client's/population's characteristics, state, needs, values, and preferences' was not viewed as an important factor in decision-making for most care providers. Although most care providers consider a woman's autonomy and bodily integrity as important, during second-stage labour, the decision for episiotomy is made by the care provider. Care providers consider that the 'trustful relationship' formed between a woman and her maternity care provider provides them with the basis of informed consent. For many care providers, consent was based on opting out, with some care providers mentioning that the state of the mother during the second stage of labour, makes it difficult or impossible to obtain informed consent and that women sometimes do not realise that episiotomy has been performed. Some placed value on informing women well about episiotomy during prenatal care. However, some of the care providers were dismissive of birth plans. They substantiated this with examples such as women having unrealistic expectations of childbirth, women's emotional and physical state during labour, and that women should relinquish control.

You can imagine the setting, right? To counsel someone at the very end of second stage labor, and to think that there is still, that there is still a real chance of knowledge and ability to weigh up the options and make a personal choice. It's not really realistic [...] In short, she (the woman) will hear it as an announcement and not as counselling. Then she can still say no if she wants, and I would listen to that. But yeah. Interviewer: And is there a kind of informed consent? Participant: Eh... eh... No... No... No [laughing]. No... (Obstetrician 11)

Where conflicts arose between a care providers' vision and woman's preferences, some care providers valued a woman's personal autonomy above their own vision. Most care providers would try to convince a woman by giving information. Others used strong convincing reasoning to change women's minds, and some disregarded a woman's autonomy. Such preferences expressed by women were often seen as a limitation to optimal care. Significantly, many care providers played down the severity of episiotomy. This was evident in the use of belittling language, such as 'just a little cut', suggesting that episiotomy was viewed by care providers as a minor intervention.

So, if you have to do an instrumental delivery (and a woman does not want episiotomy), [...] then I can roughly calculate for that lady what her chance of a sphincter injury is. [...] Using my laptop I have, within 5 minutes, what, approximately her chance is, based on the data we have. And then I say: "Well if you know that, $[\ldots]$ if you have a sphincter laceration, within 20-25 years you have a $60 \%$ chance of faecal incontinence to a greater or lesser degree, is that what you want? And if I have a reasonable method, eh, to reduce that risk. Would you want me to deprive you of this? (Obstetrician/urogynaecologist 6)

Eh well, I tell the woman, it might be that if I make a little cut now, you'll have your baby within one or two contractions. Otherwise, you'll have to push a bit 
longer... and then, eh yes, then you have... you have some kind of informed consent about whether or not she wants it (episiotomy). And usually she wants it [laughs]. (Midwife 15)

\section{DISCUSSION}

In this qualitative study, 20 care providers were interviewed about their perspectives and values towards episiotomy. The results were analysed using the framework of Satterfield $e t a l^{28}$ on EBP. This qualitative study illustrated that the expertise of the care provider themselves was the most important component in decision-making with regard to episiotomy. Care providers' perspectives, values and practices are strongly influenced by individual underlying visions of childbirth. Although care providers often emphasised the importance of a restrictive episiotomy policy, a discrepancy was expressed between vision and practice, and a large number of varying indications (see box 2) mentioned as justification for performing episiotomy. All care providers considered it important to justify their actions. While the literature was used to underpin the justification of their policies, the importance of clinical expertise was used to support deviations from recommended practice. Women's autonomy was important, yet, at the moment of decision-making, women's involvement in decision-making is minimal. Informed consent is not obtained, neither during labour, nor during pregnancy. The language often used by care providers about episiotomy illustrates an underlying attitude that views episiotomy as a minor intervention.

Understanding the perspective and values of care providers towards episiotomy is essential for obtaining deeper understanding of variations in episiotomy practices. Previous studies showed large variations in episiotomy rates. The Netherlands has historically been seen as a country with a physiological approach to childbirth and a corresponding high rate of home births. ${ }^{29}$ Studies showed that giving birth at home is a protective factor for episiotomy. ${ }^{30}$ However, although giving birth at home is more common in the Netherlands compared with all other high-income countries, the rate of episiotomy is much higher than in countries like Sweden $(6 \%$ among nulliparous women), Denmark (7\% among nulliparous women $)^{6}$ and the USA (9\%). ${ }^{31}$ This study gives insight in the underlying perspectives and values of care providers, leading to these varying episiotomy rates.

\section{Childbirth vision, evidence and practice}

The most important contributor to episiotomy practice found in our study was the vision of care providers on childbirth and episiotomy. This was rather more decisive than recommendations from the literature. Although liberal use of episiotomy has no evidence base, ${ }^{2}$ there are still countries, and regions within countries, with high episiotomy rates. ${ }^{45}$ On one hand, literature suggests that episiotomy may be beneficial to prevent OASI in some women, ${ }^{9}$ particularly in case of instrumental vaginal birth. On the other hand, routine use of episiotomy may paradoxically result in increased rates of $\mathrm{OASI}^{9}$ and overuse of episiotomy results in unnecessary problems and morbidity among many women. ${ }^{10-17}$ The awareness of these insights is reflected in the literature during the last four decades ${ }^{32}$ and has led to a decline in the episiotomy rates in many countries, with a sharper decline in some countries vs others. ${ }^{33}$ Our study showed that most care providers were aware of the importance of a restrictive episiotomy policy, but practices often diverged from this restrictive perspective, leading to a liberal rather than restrictive episiotomy practice among some care providers. In a study of Seijmonsbergen-Schermers $e t a l^{7}$ on regional variation of episiotomy in the Netherlands, a higher rate of episiotomy was found in regions with lower rates of home births. In regions with lower rates of home births, episiotomy rates in obstetrician-led care were also higher. This suggests that vision may be an important contributor to the tendency to intervene. The current study confirms this by showing widely diverging visions on episiotomy, which may be one of the most important factors leading to variation in episiotomy rates.

Moreover, previous studies confirm our finding that care providers' clinical expertise and own perspectives often override recommendations based on the literature. $^{18} 19213435$ In our study, care providers mentioned the importance that practices can be justified, although those practices and perspectives varied largely among these care providers, and were not always evidence based. Hussein $e t a l^{55}$ emphasised this by describing that care providers' preferred their familiar way of working, and that change may evoke feelings of uncertainty and risk. ${ }^{34}$ Henriksen $e t a l^{6}$ found that improving awareness of personal episiotomy rates led to a decrease in the episiotomy rate. Workload has been mentioned as barrier for reducing episiotomy rates in previous studies in settings with routine episiotomy practices, but did not emerge as a theme in our study, ${ }^{21} 34{ }^{37}$ probably because of the vision of restrictive use of episiotomy in our study. Other qualitative studies into the perspectives of care providers found various perspectives towards episiotomy. They confirm a limited role of evidence in episiotomy practice, and care providers' vision, beliefs and values being an important contributor to practice. ${ }^{181921}$

Varying perspectives on episiotomy and on dealing with evidence suggest that perspectives may not be evidence based and that evidence may be insufficiently applicable and explicit for implementation into practice. Although the literature is not clear on which indications are valid for episiotomy, it is recommended to perform episiotomies restrictively. The meaning of 'restrictive' varies largely among care providers, and recommendations in literature and guidelines are not uniform. However, in some countries national uniform recommendations on episiotomy practice are available, such as the clinical guideline 'Intrapartum care for healthy women and babies' from the National Institute for Health and Care Excellence Guidance. ${ }^{38}$ On the other hand, this guideline 
leaves room for different understandings of the clinical need for an episiotomy. In the Netherlands, national guidelines or recommendations on episiotomy practice are lacking. Recurrent evaluations of episiotomy indications with colleagues and educating care providers on the best available evidence on episiotomy will enable care providers to revise their vision and practices, and will motivate them to apply the evidence from the literature. ${ }^{39} 40$ However, educating care providers is difficult as long as there is a lack of consensus on the meaning of 'restrictive' in the literature. Future research should focus on which indications are valid for episiotomy and should be well applicable for practice, considering the complexity of situations during the second stage of labour.

\section{Woman-centered care}

The involvement of women in the decision to perform episiotomy was limited. Episiotomy is performed in a situation that is comparable to other medical emergency situations. In specific emergency situations, exceptions may apply to informed consent, because there is a lack of time to obtain informed consent ${ }^{41}$ and the woman is incapable of giving it. ${ }^{42}$ However, it is questionable whether this applies to the situation of childbirth. In accordance to Wear, ${ }^{41}$ the exception for informed consent during emergency situations involves (1) an immediate threat to life; (2) the treatment is a general recommended treatment and can appeal to the standard of practice; and (3) the time to achieve informed consent would significantly increase the risk of severe adverse outcomes. Considering the large variation in incidences and perspectives towards episiotomy, episiotomy cannot be considered a general recommended treatment or as standard practice. Stohl argued that, except from the most extreme and rare cases, childbirth is not a medical emergency and women do not typically lose the ability to make decisions during childbirth. Therefore, the exception for informed consent does not usually apply to childbirth. ${ }^{43}$ Other studies confirmed that informed consent for episiotomy is not asked for in the second stage of labour. ${ }^{445}$ Although care providers minimally involve women in the decision-making during the second stage of labour, previous studies reported that women highly value their involvement in decisionmaking during childbirth. ${ }^{46}$ Van der Pijl et al ${ }^{47}$ examined 438 quotes of women on negative and traumatic childbirth experiences, expressed in the Dutch \#breakthesilence campaign and found that lack of informed consent was one of the most frequently expressed types of mistreatment experienced by women during childbirth. Besides, episiotomy was the most frequently mentioned intervention, where women experienced a lack of communication by the care provider, which led to feelings of disrespect. Accordingly, Hollander et $a l^{48}$ found that lack of control, communication and involvement in decision-making were important attributions of traumatic birth experiences. Not being informed or not being involved in the decision to perform episiotomy can result in negative and even traumatic experiences. Although the studies of
Van der Pijl et $a t^{47}$ and Hollander et $a t^{48}$ do not represent the feelings and preferences of all women, other studies confirm that women may feel less satisfied after having had an episiotomy. ${ }^{49}$ Besides, studies show that information regarding episiotomies is important to increase understanding and feelings of comfort, ${ }^{50}$ and that being involved in decision-making is one of the most important contributors to a positive childbirth experience. ${ }^{51}$ Downe et $a t^{46}$ showed that women place high value on giving birth without non-indicated interventions, but if an intervention is needed, that they wish to be involved in decisionmaking to retain a sense of control. The difficulties concerning obtaining informed consent can be solved by shared decision-making during pregnancy about indications for episiotomy during labour if need arises. This is more feasible than during the second stage of labour, and there is enough time for the woman to form her opinion. When discussing episiotomy, care providers should be aware that women may see episiotomy as an invasive medical intervention, and that belittling words and considering episiotomy a negligible intervention may not correspond with women's feelings about undergoing it. The varying perspectives of care providers on episiotomy make it more important to involve women in decisionmaking and the appropriateness of care providers' practice should be placed in perspective, considering the varying existing perspectives and values.

\section{Strengths and limitations}

This study investigated the diverse range of perspectives and values of care providers towards episiotomy, representing all professional backgrounds. However, this study had some limitations. The perspectives of the interviewers may have encouraged participants to give socially desirable answers. Nevertheless, many participants expressed comments in favour of liberal use of episiotomy, and mentioned indications that were critically discussed in previous publications of the first authors. ${ }^{11} 5253$ On the other hand, it may have encouraged participants to express a strong opposite opinion. Conversely, by being an expert on the topic, the interviewer was able to go into the merits of the actual situations during childbirth, and to understand the difficulties care providers have to deal with. The subjectivity of the researchers may also have biased the analyses. To minimise the influence of this bias, we discussed the data and interpretation of the results within the author group that consisted of midwives, researchers, educators and an obstetrician.

Although data saturation was reached, an element of selection bias cannot be eliminated. The participants in our study represented care providers from all professional backgrounds qualified for performing episiotomies, across the whole country, and of different educational backgrounds. This resulted in a broad spectrum of perspectives and values, which will be present in other countries with similar episiotomy rates as well. Further research into the perspective and values of care providers in a variety of countries with different episiotomy rates is 
warranted to gain insight into perspectives and values of care providers working in different birth cultures. Understanding perspectives and values of care providers in various setting will provide knowledge that is required to stimulate a worldwide evaluation of episiotomy practices.

\section{CONCLUSION}

The decision to perform episiotomy was mainly based on care providers' own insight, which was highly influenced by care providers' vision on episiotomy and childbirth. Differences in care providers' perspectives, values and underlying visions may be an important contributor to the large variations in episiotomy incidences. The involvement of the labouring woman in the decision was minimal. Care providers' clinical expertise generally overruled the recommendations from the literature. The recommendation to perform episiotomies restrictively was considered important, but the large number of indications for episiotomy showed that it is in practice not always performed restrictively.

Because other literature shows that women highly value their involvement in decision-making, and a lack of feeling in-control contributes to traumatic birth experiences, women should be given the opportunity to participate in shared decision-making about indications for episiotomy, preferably during pregnancy. More research is required to achieve consensus on indications for episiotomy, and to understand perspectives and values of care providers in other settings. Future research should be well applicable for practice, considering the complexity of situations during the second stage of labour.

\section{Author affiliations}

${ }^{1}$ Department of Midwifery Science, Amsterdam UMC, Vrije Universiteit Amsterdam, AVAG, Amsterdam Public Health, Amsterdam, The Netherlands

${ }^{2}$ Research Centre for Midwifery Science, Zuyd University, Maastricht, The Netherlands

${ }^{3}$ Department of Midwifery Science, AVAG, Amsterdam Public Health Research Institute, Amsterdam, The Netherlands

${ }^{4}$ Department of Obstetrics, Leiden University Medical Centre, Leiden, Netherlands

${ }^{5}$ Academie Verloskunde Amsterdam Groningen, Amsterdam, Netherlands

${ }^{6}$ Athena Institute, VU University, Amsterdam, The Netherlands

Acknowledgements The authors thank the contribution of all participants in this study. They also thank the contribution of Davita van de Heuvel, Mandeepika Singh, and Tamar Nelson for transcribing the interviews, and Tessa Schimmel and Liduine van Hoof for interviewing three participants.

Contributors AS-S, AdJ, and TvdA conceived the study and AS-S wrote the paper. AS-S and ST interviewed the participants and conducted the analyses. AS-S, ST, EF-dJ, MS, MP, TvdA, and AdJ contributed to the methods of the study and the interpretation of the findings, and critically revised earlier drafts of the article.

Funding The authors have not declared a specific grant for this research from any funding agency in the public, commercial or not-for-profit sectors.

Competing interests All authors have completed the ICMJE uniform disclosure form at www.icmje.org/coi_disclosure.pdf and declare: no support from any organisation for the submitted work; no financial relationships with any organisations that might have an interest in the submitted work in the previous three years; relationships or activities that could appear to have influenced the submitted work, as described in the Methods section.

Patient consent for publication Not required.
Ethics approval The VU University Medical Center confirmed that ethical approval was not required for this study (reference WC2016-415). Participants signed informed consent before taking part in this study.

Provenance and peer review Not commissioned; externally peer reviewed.

Data availability statement Data are available upon reasonable request. Participant level data are available from the corresponding author at a. seijmonsbergen@amsterdamumc.nl. Participants gave informed consent for use of anonymised data for research purposes.

Supplemental material This content has been supplied by the author(s). It has not been vetted by BMJ Publishing Group Limited (BMJ) and may not have been peer-reviewed. Any opinions or recommendations discussed are solely those of the author(s) and are not endorsed by BMJ. BMJ disclaims all liability and responsibility arising from any reliance placed on the content. Where the content includes any translated material, BMJ does not warrant the accuracy and reliability of the translations (including but not limited to local regulations, clinical guidelines, terminology, drug names and drug dosages), and is not responsible for any error and/or omissions arising from translation and adaptation or otherwise.

Open access This is an open access article distributed in accordance with the Creative Commons Attribution Non Commercial (CC BY-NC 4.0) license, which permits others to distribute, remix, adapt, build upon this work non-commercially, and license their derivative works on different terms, provided the original work is properly cited, appropriate credit is given, any changes made indicated, and the use is non-commercial. See: http://creativecommons.org/licenses/by-nc/4.0/.

\section{ORCID iD}

Anna Seijmonsbergen-Schermers http://orcid.org/0000-0002-5946-2205

\section{REFERENCES}

1 EURO-PERISTAT project with SCPE and EUROCAT. European perinatal health report. Health and care of pregnant women and babies in Europe in 2010. EURO-PERISTAT $2013 \mathrm{https} / / / \mathrm{www}$. europeristat.com/images/doc/EPHR2010_w_disclaimer.pdf

2 Jiang H, Qian X, Carroli G, et al. Selective versus routine use of episiotomy for vaginal birth. Cochrane Database Syst Rev 2017;2:CD000081.

3 Graham ID, Carroli G, Davies C, et al. Episiotomy rates around the world: an update. Birth 2005;32:219-23.

4 Blondel B, Alexander S, Bjarnadóttir RI, et al. Variations in rates of severe perineal tears and episiotomies in 20 European countries: a study based on routine national data in Euro-Peristat project. Acta Obstet Gynecol Scand 2016;95:746-54.

5 , Laopaiboon M, Lumbiganon P, et al, SEA-ORCHID Study Group. Use of evidence-based practices in pregnancy and childbirth: South East Asia optimising reproductive and child health in developing countries project. PLoS One 2008;3:e2646.

6 Seijmonsbergen-Schermers AE, van den Akker T, Rydahl E, et al. Variations in use of childbirth interventions in 13 high-income countries: a multinational cross-sectional study. PLoS Med 2020;17:e1003103.

7 Seijmonsbergen-Schermers AE, Zondag DC, Nieuwenhuijze M, et al. Regional variations in childbirth interventions and their correlations with adverse outcomes, birthplace and care provider: a nationwide explorative study. PLoS One 2020;15:e0229488.

8 World Health Organization. Who recommendations: intrapartum care for a positive childbirth experience. Geneva: World Health Organization, 2018.

9 Lund NS, Persson LKG, Jangö $\mathrm{H}$, et al. Episiotomy in vacuumassisted delivery affects the risk of obstetric anal sphincter injury: a systematic review and meta-analysis. Eur J Obstet Gynecol Reprod Biol 2016;207:193-9.

10 Sartore A, De Seta F, Maso G, et al. The effects of mediolateral episiotomy on pelvic floor function after vaginal delivery. Obstet Gynecol 2004;103:669-73.

11 Seijmonsbergen-Schermers AE, Geerts CC, Prins M, et al. The use of episiotomy in a low-risk population in the Netherlands: a secondary analysis. Birth 2013;40:247-55.

12 Viswanathan M, Hartmann K, Palmieri R, et al. The use of episiotomy in obstetrical care: a systematic review. Evid Rep Technol Assess 2005;112:1-8.

13 Macleod M, Strachan B, Bahl R, et al. A prospective cohort study of maternal and neonatal morbidity in relation to use of episiotomy at operative vaginal delivery. BJOG 2008;115:1688-94.

14 Sagi-Dain L, Sagi S. Morbidity associated with episiotomy in vacuum delivery: a systematic review and meta-analysis. BJOG 2015;122:1073-81. 
15 Mulder FEM, Schoffelmeer MA, Hakvoort RA, et al. Risk factors for postpartum urinary retention: a systematic review and meta-analysis. BJOG 2012;119:1440-6.

16 Dietz HP, Shek KL, Chantarasorn V, et al. Do women notice the effect of childbirth-related pelvic floor trauma? Aust N Z J Obstet Gynaecol 2012;52:277-81.

17 Friedman S, Blomquist JL, Nugent JM, et al. Pelvic muscle strength after childbirth. Obstet Gynecol 2012;120:1021-8

18 Héman LM, van der Linden PJQ, Stigter RH. Attitude of maternity staff regarding episiotomies in an African rural hospital with high HIV prevalence: a descriptive qualitative study. Am J Trop Med Hyg 2014;90:976-9.

19 Wu LC, Lie D, Malhotra R, et al. What factors influence midwives' decision to perform or avoid episiotomies? A focus group study. Midwifery 2013;29:943-9.

20 Wu LC, Malhotra R, Allen JC, et al. Risk factors and midwife-reported reasons for episiotomy in women undergoing normal vaginal delivery. Arch Gynecol Obstet 2013;288:1249-56.

21 Schantz C, Sim KL, Ly EM, et al. Reasons for routine episiotomy: a mixed-methods study in a large maternity hospital in Phnom Penh, Cambodia. Reprod Health Matters 2015;23:68-77.

22 Ahmed HM. Midwives' clinical reasons for performing Episiotomies in the Kurdistan region: are they evidence-based? Sultan Qaboos Univ Med J 2014;14:e369-74.

23 Sagi-Dain L, Sagi S. Indications for episiotomy performance - a cross-sectional survey and review of the literature. J Obstet Gynaecol 2016;36:361-5

24 Green J, Thorogood N. Qualitative methods for health research. Thousand Oaks: Sage Publications Ltd, 2018.

25 Kelly M, Dowling M, Millar M. The search for understanding: the role of paradigms. Nurse Res 2018;25:9-13.

26 Braun V, Clarke V. Using thematic analysis in psychology. Qual Res Psychol 2006;3:77-101.

27 Attride-Stirling J. Thematic networks: an analytic tool for qualitative research. Qualitative Research 2001;1:385-405.

28 Satterfield JM, Spring B, Brownson RC, et al. Toward a transdisciplinary model of evidence-based practice. Milbank $Q$ 2009;87:368-90.

29 De Vries R. A pleasing birth: midwives and maternity care in the Netherlands. Philadelphia: Temple University Press, 2004.

30 , Brocklehurst P, Hardy P, et al, Birthplace in England Collaborative Group. Perinatal and maternal outcomes by planned place of birth for healthy women with low risk pregnancies: the birthplace in England national prospective cohort study. BMJ 2011;343:d7400

31 Kozhimannil KB, Karaca-Mandic P, Blauer-Peterson CJ, et al. Uptake and utilization of practice guidelines in hospitals in the United States: the case of routine episiotomy. Jt Comm J Qual Patient Saf 2017:43:41-8

32 Helewa ME. Episiotomy and severe perineal trauma. of science and fiction. CMAJ 1997;156:811-3.

33 Laine K, Gissler M, Pirhonen J. Changing incidence of anal sphincter tears in four Nordic countries through the last decades. Eur J Obstet Gynecol Reprod Biol 2009;146:71-5.

34 Hussein SAA. The barriers and facilitators of introducing evidencebased practices around the use of episiotomy in Jordan. University of Western Sydney, 2014. Available: http://handle.uws.edu.au:8081/ $1959.7 / 565664$
35 Hussein SAAA, Dahlen H, Schmied V. What makes episiotomy rates change?: a systematic review of the literature. Int $J$ Childbirth 2012;2:29-39.

36 Henriksen TB, Bek KM, Hedegaard M, et al. Methods and consequences of changes in use of episiotomy. BMJ 1994;309:1255-8.

37 Trinh AT, Roberts CL, Ampt AJ. Knowledge, attitude and experience of episiotomy use among obstetricians and midwives in Viet Nam. BMC Pregnancy Childbirth 2015;15:101.

38 National Institute for Health and Care Excellence. Intrapartum care for healthy women and babies. Clinical guideline [CG190]. London: NICE guideline, 2017.

39 Löwenstein L, Drugan A, Gonen R, et al. Episiotomy: beliefs, practice and the impact of educational intervention. Eur J Obstet Gynecol Reprod Biol 2005;123:179-82.

40 Skeith AE, Valent AM, Marshall NE, et al. Association of a health care provider review meeting with cesarean delivery rates: a quality improvement program. Obstet Gynecol 2018;132:637-42.

41 Wear S. Exceptions to informed consent. informed consent clinical medical ethics. Springer: Dordrecht, 1993.

42 Moore GP, Moffett PM, Fider C, et al. What emergency physicians should know about informed consent: legal scenarios, cases, and caveats. Acad Emerg Med 2014;21:922-7.

43 Stohl $\mathrm{H}$. Childbirth is not a medical emergency: maternal right to informed consent throughout labor and delivery. $J$ Leg Med 2018;38:329-53.

44 Thompson R, Miller YD. Birth control: to what extent do women report being informed and involved in decisions about pregnancy and birth procedures? BMC Pregnancy Childbirth 2014;14:62

45 Diorgu FC, Steen MP, Keeling JJ, et al. Mothers and midwives perceptions of birthing position and perineal trauma: an exploratory study. Women Birth 2016;29:518-23.

46 Downe S, Finlayson K, Oladapo OT, et al. What matters to women during childbirth: a systematic qualitative review. PLoS One 2018:13:e0194906.

47 van der Pijl MSG, Hollander MH, van der Linden T, et al. Left powerless: a qualitative social media content analysis of the Dutch \#breakthesilence campaign on negative and traumatic experiences of labour and birth. PLoS One 2020;15:e0233114.

48 Hollander MH, van Hastenberg E, van Dillen J, et al. Preventing traumatic childbirth experiences: 2192 women's perceptions and views. Arch Womens Ment Health 2017;20:515-23.

49 Calik KY, Karabulutlu Özlem, Yavuz C. First do no harm interventions during labor and maternal satisfaction: a descriptive cross-sectional study. BMC Pregnancy Childbirth 2018;18:415

50 Alexander JW, Karantanis E, Turner RM, et al. Patient attitude and acceptance towards episiotomy during pregnancy before and after information provision: a questionnaire. Int Urogynecol $J$ 2020;31:521-8

51 Hodnett ED. Pain and women's satisfaction with the experience of childbirth: a systematic review. Am J Obstet Gynecol 2002;186:S160-72.

52 Seijmonsbergen-Schermers A. Hand op de knip. Op weg naar minder episiotomieën. Tijdschrift voor verloskundigen 2017;41:32-6.

53 Seijmonsbergen-Schermers A, Ponds E, Van Driel W. Factsheet episiotomie: Royal Dutch association of midwives (KNOV), 2018. Available: https://www.knov.nl/serve/file/knov.nl/knov downloads/ 2807/file/Factsheet_Episiotomie_definitief_juni_2018.pdf 